\title{
EDITORIAL
}

\section{A REVISTA de MEDICINA do DC-FMUSP no Portal de Revistas da USP}

A Revista de Medicina é uma publicação do Departamento Científico da Faculdade de Medicina da Universidade de São Paulo. Trata-se de um periódico acadêmico-científico, direcionada aos alunos, aos docentes e aos profissionais da área de ciências da saúde, sendo a revista acadêmica ainda em circulação mais antiga do mundo. Publicada desde 1916 completou 90 anos de existência em 2006. Desde 1981 está indexada na base de dados Lilacs e a partir de 2000 na Latindex. Avaliada pela CAPES como de circulação nacional na área de ciências da saúde, o que lhe confere qualidade e prestígio, a revista está classificada nas seguintes categorias, segundo a instituição: Classificação Qualis - B5 (Medicina I, II; Medicina Veterinária, Direito e Serviço Social; B4 (Medicina III, Saúde Coletiva e Odontologia); B3 (Educação Física); C (Educação, Ciências Biológicas II e Ciências de Alimentos). Para os próximos anos, a indexação em outras bases de dados é a meta do periódico, visando cada vez mais a qualidade do que é produzido.

O Departamento Científico, ao disponibilizar o conteúdo da revista de livre acesso na Internet, vem ao encontro do que atualmente está sendo discutido no mundo todo, que é levar a informação produzida nas Instituições de Ensino e Pesquisa à toda comunidade. Desta forma, é possível difundir a Revista de Medicina publicada há mais de 90 anos pelos acadêmicos da Casa de Arnaldo.

É importante ressaltar que a revista é coordenada por um editor (sempre acadêmico de Medicina da FMUSP), que controla todo o trâmite da publicação, desde a chegada dos artigos até sua impressão final. Este acadêmico é substituído a cada ano, de acordo com as diretrizes do Departamento Científico.

A Divisão de Biblioteca e Documentação da FMUSP, através do Serviço de Promoção e Divulgação, contribui com os alunos responsáveis pela publicação da revista, na Normalização, Produção Editorial, Diagramação e Indexação.

Ademais, o periódico apoia as atividades científicas dos alunos, estimulando a leitura e publicação de artigos científicos desenvolvidos pelos acadêmicos. Atualmente, é publicada online (ISSN 1679-9836), visando divulgar e disseminar o conhecimento científico produzido pelos acadêmicos, de modo a disponibilizar online os artigos publicados através do Portal de Revistas da USP (www.revistasups.br/revistadc). Permanecendo de livre acesso, dissemina com rapidez a informação de seu conteúdo aos acadêmicos e comunidade científica do mundo globalizado.

O Portal de Revistas da USP "é a biblioteca digital das revistas publicadas por unidades de ensino e pesquisa, programas de pós-graduação e núcleos de pesquisas de docentes e alunos da USP” (SIBi/USP, 2013). O Portal é um serviço do Programa de Apoio às Publicações Científicas Periódicas da USP (criado em 1986), mantido pelo Sistema de Bibliotecas da USP, criado em 2008 com o intuito de organizar e prover o acesso livre e gratuito às revistas publicadas sob a responsabilidade da USP. Em 2012, o Portal foi remodelado, passando a utilizar o Open Journal Systems como plataforma tecnológica.

A revista está digitalizada desde 1916, com identificação de DOI para todos os artigos, sendo gradativamente colocada no Portal pelo SIBi e pela Divisão de Biblioteca e Documentação da FMUSP.

Finalizando a gestão de 2013, a revista agradece a colaboração de todos os envolvidos na publicação. Em especial aos revisores que participaram na avaliação dos artigos (Peer review) das edições desta gestão e ao grupo do DC que faz parte da Comissão Editorial e Diretoria da Revista: Adriana Kumagai, Aline Scalisse Silva - editora chefe e coordenadora da revista, Ana Carolina Schoueri, Ariadne Juna Fernandes do Prado, Bruna Fernandes de Barros, Carlos André Oshiro, Daniel Hazaki dos Santos, Jéssica Andino Adamucho, Jéssica Kazumi Okuma, Layara Fernanda Lipari Dinardi, Luiza Martins de Oliveira Ribeiro, Thiago Vicente Pereira.

\section{Referências}

SIBi-USP Portal de Revistas. Disponível em: http://www.revistas.usp.br/wp/?page_id=7.

SIBi-USP Portal de Revistas. Credenciamento. Disponível em: http://www.revistas.usp.br/wp/?page_id=724.

\author{
Aline Scalisse Silva \\ Acadêmica de Medicina da FMUSP \\ Editora chefe e coordenadora da Revista
}

